\title{
Pelas veredas da literatura comparadA \\ Olhares de Ferreira de Castro sobre o Brasil, à luz da imagologia
}

\author{
Dora Maria Nunes Gago* \\ Fundação para a Ciência e Tecnologia/ Universidade de Aveiro (Portugal)
}

\section{RES U M O}

Este artigo visa analisar, seguindo os procedimentos metodológicos da imagologia, a imagem do Brasil desenhada por Ferreira de Castro nas obras: Emigrantes, A selva e O instinto supremo. Deste modo, tentaremos compreender de que maneira a experiência de emigração vivida pelo autor é ficcionalizada, desenhando uma imagem do Brasil que se afasta do estereótipo e se enraiza numa "mitologia pessoal".

\section{PALAVRAS - CHAVE}

Literatura Comparada, imagologia, Brasil, Ferreira de Castro

\section{À LUZ DA IMAGOLOGIA...}

No presente artigo, analisaremos a imagem tecida pelo olhar do escritor português José Maria Ferreira de Castro sobre o Brasil (onde viveu entre 1911 e 1919 e que visitou posteriormente em 1959 e 1971) nas obras: Emigrantes (1928), A selva (1930) e O instinto supremo (1968), analisadas à luz da "releitura" de um dos métodos mais antigos da Literatura Comparada, a imagologia (ou seja, estudo das imagens do estrangeiro), cujas bases foram lançadas, em França, por Jean-Marie Carré com a publicação de Les écrivains français et le mirage allemand (1947).

Longo, conturbado, mas profícuo tem sido o percurso empreendido pela imagologia ao longo dos últimos cinquenta anos. No entanto, após haver sucumbido a alguns extremismos e ter sido duramente criticada, a sua evolução tem conduzido a um aperfeiçoamento, assumindo cada vez maior relevância na sociedade actual, onde o domínio da imagem é incontestável a todos os níveis.

Se, como refere Jean-Marc Moura, os pioneiros estudos imagológicos da década de 1950 haviam sido marcados por um recurso exagerado à psicologia dos povos, os

\footnotetext{
*doragago@ua.pt
} 
empreendidos nos anos 1960 foram orientados por um espírito mais positivista, ligados a um "despojamento" das fontes, ao estudo das condições ideológicas da elaboração da imagem, ao contexto histórico. ${ }^{1}$ Por seu turno, nos anos 1970 e 1980, constata-se um prosseguimento do esforço de clarificação intelectual, integrando o contributo das novas escolas críticas. Surge uma dissociação nítida entre a análise das viagens e a das imagens literárias do estrangeiro. Paralelamente, constrói-se uma teoria imagológica, de modo a delinear a especificidade literária das pesquisas e a determinar o seu lugar no campo do comparativismo.

Nessa sequência, a análise que, em seguida, empreenderemos basear-se-á sobretudo nos pressupostos teóricos de D-H. Pageaux, Álvaro Manuel Machado e de Jean-Marc Moura.

Assumindo-se como uma linguagem sobre o outro, o estudo da imagem deve considerar a sua funcionalidade e valor estético, a conformidade com um modelo, um esquema cultural que é preexistente na cultura do observador. Deste modo, partindo do conceito de imagem, dos seus elementos constituintes, é essencial conhecer os mecanismos culturais que presidiram à sua formação - neste caso concreto, nas obras de Ferreira de Castro - e o modo como, no seio de determinada cultura e de um imaginário, ela se pode ou não converter em estereótipo, ou seja, numa forma-limite, redutora e "caricatural" da imagem. Isto porque, quando um indivíduo observa uma determinada realidade, o seu espírito encontra-se já preenchido por representações colectivas através das quais a apreende, produzindo significações.

É, pois, neste contexto que se enquadra o estereótipo como elemento mediatizador da nossa relação com o real. ${ }^{2}$ Através de esquemas culturais preexistentes, o indivíduo filtra a realidade circundante. Nesta medida, a imagem não constitui um retrato fiel da realidade, mas sim uma "ficção", ou seja, uma representação cultural do elemento observado.

Definida como comunicação programada, a imagem é teoricamente constituída por três elementos: a palavra, a relação hierarquizada e o cenário, conducentes a três níveis de estudo. ${ }^{3}$

Em primeiro lugar, consideramos a palavra, ou seja, um "stock" mais ou menos restrito de palavras possibilitadoras da difusão da imagem do Outro numa determinada época e cultura. Nesse âmbito, devemos proceder a uma análise do léxico, atendendo à formação de campos lexicais e semânticos (que possibilitam o estabelecimento de isotopias).

Enfim, importa abordar todos os elementos que, ao nível da palavra, são susceptíveis de traçar um sistema de equivalência do "eu" relativamente ao "outro". Só assim é possível compreender de que modo se escreve a apropriação do estrangeiro, se nos encontramos perante uma redução do desconhecido ao familiar, ao elemento nacional, ou se, pelo contrário, constatamos uma exotização dos processos de integração cultural da realidade observada.

1 MOURA. L' imagologie comparatiste, p. 29.

2 AMOSSY. Les idées reçues, sémiologie du stéreotype, p. 26.

${ }^{3}$ PAGEAUX. La littérature générale et comparée, p. 64. 
É ainda a este nível que devemos atentar na escrita da alteridade, notando todos os elementos possibilitadores da diferenciação ou da assimilação entre o "Outro" e o "Eu".

A imagem elaborada a partir da contemplação do "Outro" pode surgir como um prolongamento do "eu" e do seu espaço de origem, transpondo metaforicamente realidades nacionais. Deste modo, esta imagem do elemento estrangeiro veicula a que o narrador tem de si próprio. Nesta sequência, a ideologia religiosa e política do escritor influencia a sua visão de outro país, de outra cultura.

Por isso, sendo a imagem que Ferreira de Castro forma do Brasil historicamente contextualizável, encontramos na sua génese, não apenas a experiência individual do autor, mas também o contexto histórico e social onde se insere.

No que se refere ao segundo momento, o das relações hierarquizadas, de inspiração estruturalista, abordando o texto na sua dimensão informativa, é necessário efectuar o seguinte percurso estruturalista: primeiramente, identificar as oposições estruturadoras do texto (por exemplo: eu-narrador-cultura de origem vs. outro, cultura representada); em seguida, focar as unidades temáticas, as pausas descritivas (constatar de que modo o elemento estrangeiro é investido de uma função particular); em terceiro lugar, atentar nas sequências onde se encontram os elementos catalisadores da imagem do estrangeiro.

Assim, é pertinente o estudo do processo de organização ou reorganização do espaço estrangeiro, as modalidades de determinação espacial e as dicotomias presentes no discurso acerca deste espaço. Verifica-se, além disso, por vezes, uma configuração do espaço através da oposição "eu" (ou cultura de origem) vs. o "outro" (ou cultura observada).

Nesta etapa, é ainda necessário não esquecer os locais que são valorizados e isolados através de um pensamento mítico, conferindo-lhes uma posição fulcral, assim como na relação entre o espaço geográfico e o psíquico. Por conseguinte, há zonas investidas de valores positivos ou negativos, permitindo a simbolização (ou "sacralização") do espaço.

Após a caracterização destes elementos enunciadores da alteridade, devemos examinar o sistema de personagens, a sua relação com o "eu", o modo como se integram num processo de inclusão ou de exclusão, o seu posicionamento cultural ou político e as suas implicações na construção textual e imagética.

Além disso, o texto deve ser entendido como um documento antropológico, no qual se expressa o sistema de valores do "outro", assumindo-se como um testemunho da cultura estrangeira. Deverá, por conseguinte, ser estudado como um processo narrativo, descritivo e também cognitivo, conducente à compreensão da génese e desenvolvimento do processo de conhecimento do escritor, face ao elemento "estrangeiro".

Após a apresentação teórica destes dois níveis de estudo, chegamos ao terceiro, de teor hermenêutico, no qual os resultados do estudo lexical e estrutural serão confrontados com os elementos históricos da época onde se integra a obra estudada. ${ }^{4}$

Em suma, a partir da palavra e das relações hierarquizadas, a imagem do estrangeiro desenvolver-se-á em temas, em sequências diversas, inscrevendo-se no texto como um cenário, conducente a uma representação simbólica do "outro".

${ }^{4}$ PAGEAUX. Trente essais de littérature générale et comparée ou la Corne d'Amalthée, p. 269. 
Esta análise permite-nos compreender se o texto se encontra ou não em conformidade com a situação social, cultural, ideológica e a tradição estética na qual se enquadra. Isto porque o escritor não copia directamente a realidade. Ele recria-a, seleccionando e reconstruindo as características consideradas mais relevantes, de acordo com a sua imaginação, a sensibilidade pessoal, as suas orientações culturais, ideológicas e literárias.

Importa, neste ponto, salientar o conceito de alteridade - um termo relacional definido a partir do "outro", ou seja, do termo complementar de referência, apontando implicitamente para algo que não se adequa dentro do horizonte de subjectividade, experiência ou expectativa, não sendo considerado como "normal".

As relações e os intercâmbios com o estrangeiro podem ser unilaterais ou bilaterais, unívocos ou recíprocos, revelando diversas atitudes no modo de encarar e transmitir a imagem do "Outro". Neste âmbito, Daniel-Henri Pageaux considerou um conjunto de atitudes que regem o cenário constituído pelo texto literário: a "mania" (o escritor considera a realidade estrangeira observada como superior à cultura de origem); a "fobia" (a realidade estrangeira é considerada, de certo modo, inferior à da cultura de origem); a "filia" (que considera a realidade cultural estrangeira positiva, integrando-a na cultura de origem, numa valorização positiva, numa estima mútua)e, finalmente, a quarta atitude, denominada cosmopolita ou internacionalista, aparentemente, que não coloca a questão de um juízo positivo ou negativo, uma vez que as relações entre as culturas se convertem tendencialmente num processo de unificação cultural.

Será pois este o nosso percurso metodológico na breve análise às imagens tecidas por Ferreira de Castro nas obras anteriormente mencionadas.

\section{Olhares de ferreira de castro sobre o brasil}

O Brasil assume na vida e na obra do escritor José Maria Ferreira de Castro um papel determinante. Foi neste país que se "forjou" a sua personalidade, através do trabalho árduo da selva amazónica, no seringal "Paraíso", onde viveu quatro anos e depois em Belém do Pará. Foi aí que ele se desenvolveu como ser humano, tendo recebido a semente que o converteu num escritor universal.

Em Emigrantes (1928), a sua primeira obra de sucesso, é relatada a odisseia de Manuel da Bouça, um emigrante português analfabeto, camponês de 41 anos, que parte para o Brasil na demanda de uma vida digna e de uma situação económica que the permita conseguir um bom dote para a filha. Para esta personagem, tal como para muitos que sonhavam emigrar, o Brasil é a Terra Prometida, o Eldorado:

Era um sonho denso, uma ambição profunda que cavava nas almas, desde a infância à velhice. O oiro do Brasil fazia parte da tradição e tinha o prestígio de uma lenda entre os espíritos rudes e simples. (...) Viam-no erguer-se refulgente, ofuscante em moedas do tamanho do sol, ao fundir-se na linha do horizonte, precisamente para os lados onde devia ficar o país maravilhoso. ${ }^{5}$

${ }^{5}$ CASTRO. Emigrantes, p. 32. 
A chegada à terra estrangeira é marcada pela curiosidade e pela ansiedade, perante o novo mundo que lhes surge. São de deslumbramento as primeiras imagens colhidas: "Era uma surpresa de luz, de cor e de linhas - um 'ah!' que surgia, inevitável, nos espíritos deslumbrados."

No entanto, após o desembarque, as formalidades, a burocracia e a quarentena a que estão obrigados os membros do "rebanho" (como são múltiplas vezes referidos), inicia-se a "saga" de Manuel da Boiça para encontrar um emprego remunerado por um salário condigno. Nesse contexto, Manuel da Bouça recria a desilusão sentida pelo jovem Ferreira de Castro, ao procurar a "Casa Samuel" (indicada pelo seu acompanhante), onde esperava encontrar o emprego desejado.

Perante as inúmeras dificuldades e as informações que Cipriano (que também vive em condições precárias) lhe vai fornecendo, relativamente aos baixos salários e à exploração de que são vítimas os trabalhadores, Manuel começa a sentir os seus sonhos a desmoronarem-se. Por fim, por intermédio da Agência Oficial de Colocação, é enviado para um cafezal na Fazenda de Santa Efigénia, perto de Ribeirão Preto.

$\mathrm{Na}$ fazenda de Santa Efigénia, a remuneração era má, as condições de trabalho muito duras. Acentuava-se a ideia de injustiça social, pois o proprietário esbanjava dinheiro, enquanto os trabalhadores eram profundamente explorados, entregues quase a um trabalho escravo. Assim, os senhores das terras desfrutavam de absoluta autoridade sobre os seus trabalhadores como acontece com o coronel Borba e o feitor Capristano, que representam o poder despótico sobre os mais fracos, que tinham como única hipótese a resignação.

Na relação com o "outro", Manuel da Boiça, devido à sua pouca instrução e ao facto de não saber ler, revela, por vezes, uma certa incomunicabilidade. Inicialmente, tem dificuldade em perceber o português do Brasil, depois, vai na fazenda partilhar a casa com um italiano com quem só consegue comunicar por linguagem gestual.

A evocação da família e da terra natal são uma constante, desencadeadas por diversos pormenores: o canto familiar de um grilo, a semelhança que encontra entre a colheita do café e o trabalho da ceifa na sua aldeia nativa. Assim, a terra natal acaba por ser o eixo configurador a partir do qual é vista e apreendida a realidade estrangeira: "Pouco a pouco, na paisagem tropical sobrepôs-se, para os olhos de Manuel da Bouça, a paisagem da sua terra - da sua aldeia esquecida num recanto de Portugal (...) Os cafeeiros iam-se transformando em giestas e as 'ruas' do cafezal em ínvios caminhos (...)."7

Deste modo, constata-se na personagem a tendência constante para aproximar a realidade estrangeira da do país de origem, numa tentativa de integração, de aproximação entre os dois "mundos".

$\mathrm{Na}$ fazenda, é alvo da paixão da mulata Benvida, que lhe atenua a solidão, a sensação de desintegração.

Terminado o trabalho, Manuel parte para São Paulo para trabalhar num armazém, alimentando novas esperanças. Assim, ao acompanharmos a personagem nesta

\footnotetext{
${ }^{6}$ CASTRO. Emigrantes, p. 104.

${ }^{7}$ CASTRO. Emigrantes, p. 197.
} 
experiência urbana, constatamos que o futuro que lhe é oferecido continua a ser mesquinho e o salário apenas lhe assegura a subsistência. Neste ponto, conhecemos as lutas operárias que começam a desencadear-se nesse espaço, juntamente com a revolução de Julho de 1924, ocorrida em nesse estado e liderada pelo general Isidoro Dias Lopes. Note-se que Manuel participa nestas lutas de forma receosa e pouco esclarecida, temendo assumir uma atitude activa, nunca ultrapassando uma posição meramente individualista. Tal como refere Nelly Coelho, é nesta segunda parte do romance que é registado "o drama social, económico e político que não foi (e não é...) só nosso mas do mundo inteiro, a partir do momento em que a urbe (...) foi tornando superadas e insustentáveis as antigas formas do viver rural." 8

Contudo, sete anos volvidos, ao partir, tão miserável como chegou, Manuel sente a nostalgia de abandonar a terra de exílio: "Agora que ia abandoná-la, a terra de exílio ligava-se-lhe por uma suave melancolia, como por uma saudade que ele viria a sofrer uma saudade da terra e de quem nela vivia, de Benvida, do Fernandes (...) e até das horas ruins". 9

Além disso, o regresso ao país natal não lhe traz a alegria imaginada. Pesa-lhe o fracasso, a vergonha, o receio que os seus conterrâneos descubram a sua situação económica, a antevisão das humilhações. Decide, por isso, partir para Lisboa, quando se apercebeu da mudança operada no seu ser, pois a sua identidade redesenhou-se, redefiniu-se, no seio da realidade distante, no contacto com a cultura e o povo longínquos, na dureza da vida experimentada.

Em A selva, o caso de Alberto é diferente. Encontra-se em Belém do Pará, na casa do tio Macedo, que o vê como um fardo: sabe-se que ele trabalhava num armazém, mas foi despedido devido à crise económica que vivia na época. O tio envia-o para a Amazónia, onde terá de trabalhar como seringueiro. A sua situação é completamente diferente da de Manuel da Bouça: é um jovem de 26 anos que frequentava o 4⿳o ano do curso de Direito, exilado por motivos políticos. Os seus ideais monárquicos levaram-no a envolver-se nos confrontos de Monsanto e o triunfo dos republicanos conduziu-o ao exílio, primeiro para Espanha, depois para o Brasil. Trata-se, pois, de um jovem culto, "elitista", para quem a condição de quase "escravo" num seringal e de "emigrante de $3^{\text {a }}$ classe" (experiência vivida também pela personagem Manuel da Bouça e pelo próprio Ferreira de Castro) constituirão experiências profundamente dolorosas. Mais uma vez, a imagem do "rebanho" no seu "curral" revela expressivamente as condições em que se deslocam os emigrantes. Em contrapartida, a figura de Alberto contrasta com os outros, até a nível do vestuário, pois o seu terno passado a ferro e a gravata às riscas destoam do ambiente miserável dos passageiros da terceira classe.

Do mesmo modo, Alberto assume-se como "alter ego" do autor, visto que as dificuldades e a dureza da vida experimentadas no seringal, na recolha da borracha, as condições de trabalho próximas da escravatura, o poder do cenário exótico da floresta devoradora, animalizada, a desumanização produzida nos homens pelas condições atrozes,

\footnotetext{
${ }^{8}$ COELHO. A presença do Brasil na vida e na obra de Ferreira de Castro, p. 30-31.

${ }^{9}$ CASTRO. Emigrantes, p. 253.
} 
todos estes aspectos foram sentidos por Ferreira de Castro, durante quase quatro anos (desde o início de 1911 até 1914), tendo determinado a sua evolução, o seu amadurecimento pessoal.

Constata-se que, no espaço de exílio, o país de origem assume-se como uma miragem, algo de irreal, que parece apenas habitar a memória. Ao atravessar terras com nomes portugueses (Alenquer, Faro, Óbidos) durante a viagem, o protagonista apropria-se dos feitos históricos dos descobridores e colonizadores portugueses, revelando a importância da História e da cultura de origem na configuração do olhar face ao "Outro": "Agora, porém, as façanhas que a história atribuía aos ancestrais doiravam-se fortemente, fazendo-o vibrar como se fossem pertença sua, como se houvessem sido cometidas por ele próprio (...) ${ }^{10}$

Os sentimentos de isolamento, revolta, indignação e, sobretudo, de desintegração principiam a sentir-se ao longo da viagem no "Justo Chermont", visto que ele não se identifica com a gente "sórdida e promíscua" que o acompanha. Neste ponto, a personagem contempla o "outro" (neste caso os outros emigrantes) com uma atitude que se aproxima da "fobia", visto que o considera inferior. Posteriormente, já no seringal, a sua alvura e porte urbano convertem-no em alvo de escárnio, acentuando-se a solidão e o isolamento.

Nesta sequência, o drama de Alberto e o seu percurso individual centram-se num único espaço: a selva amazónica. A selva reveste-se de tal importância que, além de espaço, assume quase a condição de personagem, visto que constantemente é animizada, comparada a uma "fera devoradora", ${ }^{11}$ ou "monstro". ${ }^{12}$ Desenhada como entidade déspota, aniquiladora dos últimos rasgos de humanidade dos homens, ela atrai, fascina, aterroriza, domina:

A selva dominava tudo. Não era o segundo reino, era o primeiro em força e categoria, tudo abandonando a um plano secundário. E o homem simples transeunte no flanco do enigma, via-se obrigado a entregar o seu destino àquele despotismo. (...) Dir-se-ia que a selva tinha, como os monstros fabulosos, mil olhos ameaçadores que espiavam de todos os lados. ${ }^{13}$

No entanto, como considera António Cândido Franco, ${ }^{14}$ paralelamente a esta imagem negativa da selva destruidora, devoradora, geradora de angústia, de pânico, que no fundo representa a própria sociedade, também ela "devoradora" dos mais desprotegidos, como é o caso dos seringueiros), encontramos uma outra faceta, a de geradora de vida, uma espécie de "mãe" grandiosa e fértil: "Solo de constantes parturejamentos, obstinado na ânsia de criar, a sua cabeleira contemplada por fora, sugeria vida liberta

${ }^{10}$ CASTRO. A selva, p. 42.

${ }^{11}$ CASTRO. A selva, p. 80.

${ }^{12}$ CASTRO. A selva, p. 88.

${ }^{13}$ CASTRO. A selva, p. 88.

${ }^{14}$ FRANCO. O significado da selva na obra de Ferreira de Castro, p. 63-65. 
num mundo virgem, ainda não tocado pelos conceitos humanos (...) Só a luz obrigava o monstro a mudar de fisionomia." 15

Deste modo, a selva reflecte a realidade social e cultural do homem, assumindose, nesta medida, como um sistema simbólico de representação social.

Assim, esta outra face, de conotação positiva, poder-se-á relacionar igualmente com o aspecto positivo da sociedade, ou seja, no meio das injustiças sociais, Alberto encontra, no seringal, entre os companheiros, sobretudo com Firmino, uma grande solidariedade.

Por conseguinte, ao longo do tempo, as mudanças operadas em Alberto são notórias. A princípio, é dominado pela sensação de aprisionamento, isolamento, solidão, sendo posteriormente vencido pela força tirana da selva, que o leva à submissão, ao desânimo e ao completo desleixo no aspecto físico que tanto prezava, numa descida ao seu próprio abismo interior, à degradação dos sentidos. Esta grande transformação é acompanhada por outra da mesma dimensão, de teor psicológico. A personagem evolui notavelmente, através do seu contacto com o "outro", sobretudo com Firmino, um mestiço oriundo do Ceará que é o seu companheiro de seringal, com os seringueiros irmanados com ele na mesma miséria, encarcerados no mesmo espaço claustrofóbico, dissolvente que lhes retira a humanidade e a dignidade. Nesta sequência, o jovem arrogante, orgulhoso, convicto dos seus ideais políticos, elitistas, torna-se mais humano, humilde, revelando uma abertura e compreensão face ao outro, num exercício de alteridade, marcado pelo encontro e a compreensão: "A pensar nas bravas gentes, Alberto enternecia-se agora e compreendia-as melhor. Já eram outras para ele, assim vestidas com farrapos dramáticos que a Europa ignorava." ${ }^{16}$ Neste caso, a sua atitude perante o outro evolui notoriamente da "fobia" para a "filia".

Seguidamente, a vida de Alberto melhora, visto que passa a trabalhar no escritório do seringal, com condições completamente diferentes das anteriores. No entanto, não esquece as condições de vida dos companheiros e ao recordá-las, revolta-se contra as injustiças de que são vítimas, num conflito interior que põe em causa todos os valores que antes defendera. Por fim, uma carta da mãe informa-o de que poderá voltar à terra natal, pois os republicanos amnistiaram os insurrectos de Monsanto.

Assim, num processo gradual de aprendizagem, Alberto modifica-se completamente, renovando-se, pondo de parte o seu passado, através da construção de uma identidade renovada, mais consciente:

"Os republicanos... Os monárquicos..." Tudo aquilo lhe soava imprevistamente a oco, longínquo e sem sentido. Arrefecera-lhe a paixão, as suas antigas idéias pareciam-lhe de tempos remotos, dum outro eu que se perdera e se esfumara na lonjura. (...) Cada vez sentia menos o domínio das teorias que o haviam forçado a emigrar e parecia-lhe mesmo que sobre elas se iam condensando, de modo mal definido, uma razão diferente e um sentimento de justiça nova, mais profunda e mais vasta. ${ }^{17}$

\footnotetext{
${ }^{15}$ CASTRO. A selva, p. 88.

${ }^{16}$ CASTRO. A selva, p. 135.

${ }^{17}$ CASTRO. A selva, p. 193.
} 
Deste modo, a ânsia de partir torna-se cada vez mais intensa, mas, à semelhança do que sucedeu com Manuel da Bouça, também Alberto continua pobre, tendo a mãe de lhe pagar a passagem de regresso.

No final, constatamos que o protagonista, que desde o início se sobrepõe como herói, encarnando as aspirações dos seringueiros, transformou-se num humanista que defende a justiça para todos. Aliás, após o incêndio provocado pelo negro Tiago para assassinar o tirano Juca, inimigo da liberdade, peça fundamental do sistema de exploração e opressão, que mandou chicotear os seringueiros que haviam fugido, Alberto conclui que nunca será advogado de acusação: "Não. A sua voz não poderia abrir-se em grandes tropos acusadores (...) Dedicar-se-ia ao cível, à carreira consular ou à defesa, só à defesa, se a necessidade o obrigasse a debruçar-se sobre o pego insondável dos delitos humanos." ${ }^{18}$

Deste modo, Alberto aspira a um mundo mais humano e mais justo, a uma justiça universal, abandonando os seus ideais retrógrados e adoptando outros de teor humanista e progressista.

Por seu turno, de teor completamente diverso é o último romance gerado pelo autor, intitulado $O$ instinto supremo (1968), em cuja génese esteve a promessa feita ao general Cândido Rondon, humanista e desbravador da Amazónia. Centra-se, pois, em factos históricos, ou seja, na grandeza da aventura missionária protagonizada por uma expedição de um grupo de Rondon, que, em 1922, procura aproximar-se pacificamente dos temidos índios Parintintins.

Revela-nos a obra que o "instinto supremo" da autoconservação torna-se secundário perante um valor maior, o da solidariedade humana. Neste caso, não é a ambição que comanda as personagens, mas sim o desejo de integrar os índios num sistema de vida mais civilizado, vencendo a barbárie. Por isso, o grandioso lema que os norteia é: "Morrer se necessário for; matar, nunca!"19

A acção deste romance é linear. Nos primeiros capítulos, assistimos ao desbravamento da mata para a instalação do acampamento, à chegada de Curt Nimuendajú, um etnólogo alemão, naturalizado brasileiro, ao recrutamento do grupo e à ida para a floresta. Constatamos que também para este "emigrante" europeu o Brasil se assume como a terra de oportunidades, onde poderá realizar o seu sonho de etnólogo autodidacta; assim "o Brasil imenso surgialhe, por detrás das névoas da lonjura, como o país que lhe era necessário (...)”. ${ }^{20}$

No capítulo VII, é erguido o acampamento, realiza-se o primeiro contacto hostil com os índios e sucedem-se vários episódios de confronto, com o objectivo da pacificação. Finalmente, com o recurso a um intérprete a comunicação com os índios adquire eficácia e, no capítulo XII é conseguida a ambicionada pacificação. Resume-se, então, o encontro entre dois "Brasis": o civilizado e o selvagem. Aliás, de notória fraternidade são as palavras de Rondon no discurso que elabora: "Os índios são nossos irmãos, são mesmo os mais brasileiros dos brasileiros." ${ }^{21}$

${ }^{18}$ CASTRO. A selva, p. 248.

${ }^{19}$ CASTRO. O instinto supremo, p. 30.

${ }^{20}$ CASTRO. O instinto supremo, p. 111.

${ }^{21}$ CASTRO. O instinto supremo, p. 41. 
Também nessa obra, como sucedia em A selva, a função da natureza, mais especificamente da selva, é dupla. Por um lado, ela é fonte de emoção e deslumbramento: "(...) sobre ela parecia baixar, vinda dos tormentos iniciais do Universo, uma poesia épica, soturna e densa, que aguardaria apenas a hora de poder exprimir o inefável (...)." ${ }^{22}$ Por outro lado, ela é uma força destrutiva, aniquiladora, monstruosa, que destrói aquilo que o Homem constrói. Espelha-se, pois, o duelo entre a Natureza e a Civilização e a História. Tal facto evidencia-se, quando o local onde Feliciano foi sepultado é desfigurado, como se a floresta quisesse recuperar aquilo que o ser humano lhe quer extorquir: "Vasta plantaria, obedecendo à vitalidade duma natureza alucinada, desenvolvera-se tão exuberantemente sobre o chão (...) que (...) ninguém imaginaria que há muito pouco ainda se enterrara ali um homem." 23

Na verdade, tal como refere Jacinto Prado Coelho, essa obra assume-se como epopeia, reveladora da luta vitoriosa do Homem contra a Natureza, "essa luta que dá um sentido à vida e um motivo para o Homem se orgulhar da sua dignidade". ${ }^{24}$ À semelhança do que sucede nas outras obras do autor, é o profundo humanismo e a fraternidade que percorre cada uma das suas páginas.

Podemos constatar, assim, que nas três obras que constituem o nosso corpus se desenham uma série de dicotomias, contrastes através dos quais se desenha o retrato do Brasil, entre as quais podemos salientar: selva vs. cidade; civilização vs. barbárie; cultura vs. natureza; opulência vs. miséria; trabalhadores vs. patrões; crueldade vs. solidariedade; vida vs. morte. De entre estes eixos antitéticos podemos destacar o primeiro (cidade/selva), visto que os outros acabam por dele derivar. Por outras palavras, o espaço privilegiado pelo autor, embora investido de ambivalências é o da selva (dominante em A selva e O instinto supremo) o rural (presente na Fazenda de Sta. Efigénia de Emigrantes). No entanto, é precisamente nesse espaço mitificado que se desenrolam todas as outras dialécticas, notando-se uma clara preferência "telúrica" pela natureza incorrupta. Apesar disso, o fascínio pela cidade (aparentemente conotada com a opulência, a civilização, a cultura, mas também a corrupção) também surge, principalmente nas duas primeiras obras. Nessa sequência, Em A selva, Manaus é a cidade luminosa, moderna, símbolo do futuro, que surge em todo o seu esplendor: "Manaus era um clarão radioso na noite amazonense. A sua poalha luminosa erguia-se até muito alto, empalidecendo as estrelas que espreitavam lá de cima.". ${ }^{25}$ Nesta linha, a exaltação modernista do progresso, a marca da civilização urbana é igualmente visível em $O$ instinto supremo, contrastando com a realidade da selva:

Mais além, iam-se acumulando fardos, caixas, barricas, outros volumes, com marcas industriais de belas cidades do Sul e de famosos países estrangeiros, que, lembrados ali na terra cercada pela floresta indomada, dir-se-iam irreais, assombrosas urbes da imaginação criadas compensadoramente em acres momentos de soledade. ${ }^{26}$

\footnotetext{
22 CASTRO. O instinto supremo, p. 143.

${ }^{23}$ CASTRO. O instinto supremo, p. 139.

${ }^{24}$ COELHO. O instinto supremo: quando a ética se torna humanitária, p. 49.

${ }^{25}$ CASTRO. A selva, p. 54.

${ }^{26}$ CASTRO. O instinto supremo, p. 37-38.
} 
Do mesmo modo, em Emigrantes, é-nos transmitido o fascínio do protagonista pelo Pão de Açúcar, pela Baía de Guanabara e, sobretudo pela grandiosidade, vitalidade e animação do Rio de Janeiro, cidade representada simbolicamente como gigantesca metrópole do futuro: "Manuel da Bouça, (...) extasiando-se ante a obra, apenas lobrigada que aquele pedaço da Humanidade criava e desenvolvia, com febril potência e sentido civilizador, na outra margem do Atlântico."27

Em oposição à selva, a cidade é o espaço do progresso, da cultura, da civilização, da arte e da diversão, assumida como uma outra faceta do Brasil, marcado como já referimos pelos contrastes.

Assim, prosseguindo a linha iniciada em Emigrantes, A selva impõe uma tomada de consciência da realidade, numa linha precursora do Neorrealismo denunciando a exploração desumana de que eram vítimas os emigrantes, que partiam para a "terra prometida" em busca do Eldorado, que rapidamente era desmitificado e desembocava no mais cruel pesadelo. Nesta sequência, em A selva é denunciada, mais uma vez, e neste caso de forma mais concreta e detalhada a injustiça e a desumanidade que corroíam a organização social da época, o "vampirismo" dos patrões, que, aspirando apenas ao lucro fácil, escravizavam os seringueiros.

Nestas duas obras, Ferreira de Castro transpôs para as suas personagens o sonho do Eldorado que atraiu tantos emigrantes, inclusive ele próprio, a uma terra desconhecida, vista a distância como espaço de abundância, de liberdade de realização. No entanto, à semelhança do que sucedeu com muitos dos que partiram comandados pela força do sonho, depararam-se com a miséria, o fracasso e o pesadelo. Apesar de tudo isso, este insucesso é atribuído à organização social e às injustiças que a minam, mas nunca ao Brasil, do qual nos é fornecida, apesar de tudo, uma imagem positiva, utópica. Assim, o autor revela-se um admirador do Brasil, da sua paisagem e cultura, partilhando os seus valores fulcrais. Nesta esteira, como refere Emery, é notória a relação existente entre a tropicalidade vivida e o humanismo do escritor, uma vez que: "Il s'agit d'une vision originale du tropicalisme, qui sait s'abstraire du stéreéotype éculé, mais qui garde encore un fond optimiste, caractéristique d'un humanisme 'rousseauiste' et positif."28

Em todas as obras analisadas, as características da realidade brasileira, a imagem do "Outro" são transmitidas objectivamente, através do recurso a um léxico que fornece informações concretas sobre a fauna, a flora e aspectos concretos da selva amazónica (o que sucede sobretudo em A selva e $O$ instinto supremo). Além disso, os diálogos reproduzem o léxico e a organização sintáctica características do português do Brasil, surgindo ainda, em certos casos, a preocupação de reproduzir a pronúncia das classes populares. Um exemplo é: "Posso remar, si siô, como um moço. Não sou nenhum perereca (...)"; "Se é muito bobo quando não se tem experiência! Eu ficava à minha porta a ver chegar ela toda sassariqueira $(\ldots)^{30}$ ou ainda nas falas de Benvida: "Num quero, seu Manué. Lhi

${ }^{27}$ CASTRO. Emigrantes, p. 110.

${ }^{28}$ EMERY. L'humanisme luso-tropicale selon José Maria Ferreira de Castro, p. 89.

${ }^{29}$ CASTRO. O instinto supremo, p. 65.

${ }^{30}$ CASTRO. O instinto supremo, p. 186. 
agradeço, mas num quero. Você tem muié e num é daqui." ${ }^{11}$ Deste modo, a "brasilidade" é captada e retratada, através de alcunhas como "galego", português, "carcamando", o estereótipo que associa sempre o português ao comércio, ou ainda, particularmente em A selva, mediante a descrição dos caboclos como muito ligados à sua cama de rede e à cachaça.

Portanto, o Brasil exótico, desenhado na mente dos camponeses portugueses como o Eldorado, é desmitificado por Ferreira de Castro, delineando-se como uma terra crua, onde, paralelamente coexistem a miséria, a exploração, o trabalho árduo, o sucesso e a fortuna.

Por último, resta-nos lembrar que, sendo o Brasil configurado como espaço de exílio, marcado pelo fracasso em âmbito económico, ele assume uma vertente positiva, ao desenhar-se, por outro lado, como local de encontro com um mundo desconhecido, exótico e enriquecedor, com um "Outro" diferente do "eu" que, no cenário do trabalho árduo do cafezal ou da floresta amazónica, revela solidariedade, estabelecendo laços de amizade (basta recordarmos Manuel da Bouça e o companheiro italiano ou Alberto e Firmino), assentes na entreajuda, no esforço de compreensão que atenuam a solidão e a saudade sentidas pelos emigrantes.

De modo geral, é muito positiva a imagem do país estrangeiro, reveladora de uma verdadeira filia face ao outro, enraizada numa espécie de "mitologia pessoal" que se afasta do estereótipo. Isto porque rompe com uma espécie de "tradição" que representava o Brasil como um local exótico, convertendo essa riqueza ilusória e prazeres em desilusões que não afectam, contudo, a admiração revelada pelo país, pela sua gente e cultura. literária do século. Percursor do neorrealismo, o autor preocupou-se essencialmente em descrever a realidade, denunciar as injustiças, a opressão, e, por outro lado, acentuar o humanismo civilizador de alguns homens.

Em suma, o Brasil é o espaço da renovação e da mudança, conducente à construção de uma nova identidade, a partir da instauração de um processo de alteridade. Por conseguinte, apesar de todos os desencontros, desilusões e pesadelos, ele delineia-se, sobretudo, como um lugar de encontro, de construção de conhecimento e de reconstrução da identidade pessoal, apesar de todos os sonhos e esperanças naufragadas, elevando-se como um hino de esperança num futuro promissor.

${ }^{31}$ CASTRO. Emigrantes, p. 183. 


\section{RESUMÉ}

Ce texte prétend analyser, en suivant les principes de l'imagologie, l'image du Brésil esquissée par Ferreira de Castro dans les œuvres Emigrants, Forêt vierge et l'Instinct suprême. Nous essayerons, ainsi, de comprendre comment l'expérience de l'émigration vécue par l'écrivain a été fictionnalisée, en dessinant une image du Brésil que s'éloigne du stéréotype et s'enracine dans une mythologie personnelle.

\section{MOTS-CLÉS}

Littérature Comparée, imagologie, Brésil, Ferreira de Castro

\section{REFERÊNCIAS}

AMOSSY, Ruth. Les idées reçues, sémiologie du stéreotype. Paris: Ed. Nathan, 1991. p. 150. BRASIL, Jaime. Ferreira de Castro: a obra e o homem. Lisboa: Ed. Arcádia, 1961. p. 273. CASTRO, Ferreira de. O instinto supremo. Lisboa: Guimarães Editores, 1968. p. 364.

CASTRO, Ferreira de. Emigrantes. 21. Ed. Lisboa: Guimarães Editora, 1980. p. 290.

CASTRO, Ferreira de. A selva. 40. ed. Lisboa: Guimarães Editora, 2006. p. 256.

COELHO, Jacinto do Prado. O instinto supremo: quando a ética se torna humanitária. In: . Memoriam de Ferreira de Castro. Introdução e estruturação de Adelino Vieira Neves. Cascais: Arquivo Bio-bibliográfico dos Escritores e Homens de Letras de Portugal, 1976. p. 47-49.

COELHO, Nelly Novaes. A presença do Brasil na vida e na obra de Ferreira de Castro. Separata do Boletim Bibliográfico Biblioteca Mário de Andrade, São Paulo, v. 41, n. 1,2, p. 6-38, jan.-jun 1980.

EMERY, Bernard. L'humanisme luso-tropicale selon José Maria Ferreira de Castro. Paris: Ellug, 1992. p. 229.

FRANCO, António Cândido. O significado da selva na obra de Ferreira de Castro. Revista Colóquio Letras, n. 104/105, p. 62-68, jul. 1988.

GAGO, Dora Maria Nunes. Imagens do estrangeiro no Diário de Miguel Torga. Lisboa: Fundação Calouste Gulbenkian/FCT, 2008. p. 335.

JESUS, Maria Saraiva de. O Brasil na vida e na obra de Ferreira de Castro. Folhas, Letras, Outros Ofícios, Ano III, n. 3, Aveiro: Grupo Poético de Aveiro, p. 30-37, jun. 1998. MARTINS, Otília Pires. "A alteridade: conceito e representações; preâmbulo", Portugal e o "Outro": imagens e viagens (Coord. Otília Pires Martins). Centro de Línguas e Culturas, Universidade de Aveiro, Imprensa de Coimbra, 2004. p. 9-11.

MOURA, Jean-Marc. L'imagologie littéraire: tendances actuelles. In: . Perspectives comparatistes. Études réunies par Jean Bessière et Daniel-Henri Pageaux. Paris: Honoré Champion, 1999. p. 27-38.

PAGEAUX, Daniel-Henri. La littérature générale et comparée. Paris: Armand Colin, 1994. p. 220. 
PAGEAUX, Daniel-Henri. Trente Essais de littérature générale et comparée ou la corne d'Amalthée. Paris: Ed. L'Harmattan, 2003. p. 318.

VIEIRA, Nelson H. Brasil e Portugal, a imagem recíproca. Lisboa: Ed. Instituto de Cultura e Língua Portuguesa, 1991. p. 249. 